71 patients accepted zolendronic acid, the others accept other anti-osteoporotic agents. $35(49.3 \%)$ of zolendronic acid had increased creatinine, while 379 $(41.3 \%)$ of non-zolendronic acid had creatinine changes $(p=0.117)$. After adjust variables, zolendronic acid did not increase creatinine ( $p=0.291$; OR: $0.750 ; 95 \%$ Cl: 0.440-1.279).(Table 1)

Table 1. Risk of increase in renal function in zolendronic acid after adjust variables

\begin{tabular}{lccccccc}
\hline & Regression coefficient & S.E. & Wald & P value & OR & \multicolumn{2}{c}{ 95\% C.l.for OR } \\
\cline { 6 - 9 } & & & & & & Lower & Upper \\
\hline Zoledronic acid & -0.288 & 0.273 & 1.116 & 0.291 & 0.750 & 0.440 & 1.279 \\
Smoking & 0.250 & 0.343 & 0.533 & 0.465 & 1.284 & 0.656 & 2.513 \\
Alcohol & 0.025 & 0.065 & 0.147 & 0.702 & 1.025 & 0.903 & 1.164 \\
BMl & 0.007 & 0.017 & 0.160 & 0.689 & 1.007 & 0.974 & 1.040 \\
DM & -0.165 & 0.164 & 1.022 & 0.312 & 0.848 & 0.615 & 1.168 \\
HTN & -0.418 & 0.149 & 7.856 & 0.005 & 0.658 & 0.491 & 0.882 \\
\hline
\end{tabular}

Conclusions: Zolendronic acid use did not lead to increase in creatinine as compared with the control group. However it need more cases to confirm this findings.

References:

[1] Miller PD Bone. 2011 Jul;49(1):77-81.

Acknowledgements: We thanks Chang Gang Memorial Hospital for data support. Disclosure of Interest: None declared

DOI: 10.1136/annrheumdis-2017-eular.3087

\section{AB0860 THE PREDICTORS FOR 24 MONTHS EFFICACY OF DENOSUMAB, AN ANTI-RANKL ANTIBODY, ON OSTEOPOROSIS IN PATIENTS WITH RHEUMATOID ARTHRITIS FROM MULTICENTER STUDY (TBCR-BONE)}

Y. Hirano ${ }^{1}$, Y. Kanayama ${ }^{2}$, N. Takahashi ${ }^{3}$, N. Ishiguro ${ }^{3}$, T. Kojima $^{3}$. ${ }^{1}$ Rheumatology, Toyohashi Municipal Hospital, Toyohashi; ${ }^{2}$ Orthopaedic Surgery and Rheumatology, Toyota Kosei Hospital, Toyota; ${ }^{3}$ Orthopaedic Surgery and Rheumatology, Nagoya University Graduate School of Medicine, Nagoya, Japan

Background: Although medication of rheumatoid arthritis (RA) has been improved by early intensive treatment using csDMARDs, tsDMARDs and bDMARDs for decades, treatment of concomitant disease in RA patients, such as osteoporosis (OP), will be more important to improve activity of daily living of RA patients. Although denosumab (DMB), an anti-RANKL antibody, was approved for treatment of OP in Japan in 2013, clinical data in real world is lacking in patients with RA. We reported 12 months efficacy of denosumab on osteoporosis in patients with RA at EULAR 2016 in London ${ }^{11}$. Here we report results for 24 months.

Objectives: To investigate the 24 months efficacy of denosumab (DMB) on osteoporosis in patients with rheumatoid arthritis (RA-OP) and to explore predictors of efficacy from multicenter study (TBCR-BONE).

Methods: 59 female cases with RA-OP treated with DMB for 24 months were included in this study. Bone mineral density (BMD) of lumbar spine (LS-BMD) and total hip (TH-BMD) and serum bone turnover markers (P1NP and TRACP-5b) were measured at baseline and every 6 month until 24 months. Spearman's rank correlation coefficient was calculated between \%increase of BMD at 24 months and various data (baseline patients' characteristics, parameters of RA disease activity [DAS28-CRP, SDAI, CRP, MMP-3] and bone turnover markers (BTMs) [P1NP and TRACP-5b]). Time averaged data (ta-data) which was averaged data of every 6 month was utilized for analysis with respect to data of RA disease activity and BTMs besides baseline data.

Results: Mean age was 59 years old. Mean RA duration was 16 years. Rates of concomitant prednisolone use was $33.9 \%$. Mean DAS28-CRP was 2.7 . $44 \%$ of cases had the past history of fracture. Mean FRAX was 28\%. Daly teriparatide was used in 11 cases before DMB treatment. \%increase of LSBMD at every 6 month was significantly increased $(4.7 \%>6.7 \%>7.7 \%>8.3 \%)$ and $\%$ increase of THBMD
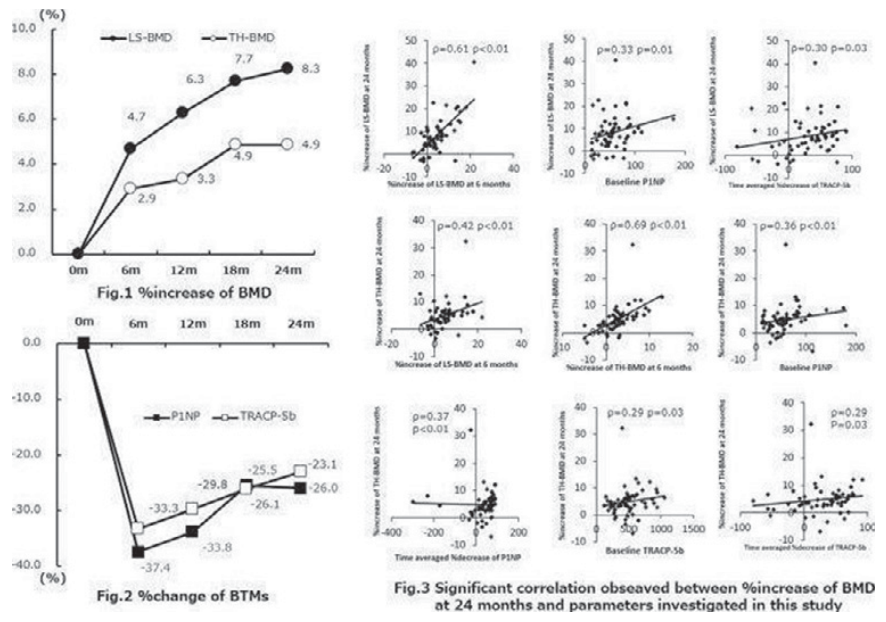

at every 6 month was significantly increased $(2.9 \%>3.3 \%>4.9 \%>4.9 \%)$ (Fig1). $\%$ decrease of P1NP and TRACP-5b was $37.4 \%>33.8 \%>25.5 \%>26.0 \%$ and $33.3 \%>29.8 \%>26.1 \%>23.1 \%$, respectively (Fig2). Fig3 showed that parameters (correlation coefficient) which were correlated with \%increase of LSBMD at 24 months were \%increase of LSBMD at 6 months $(0.61)$, baseline P1NP $(0.33)$ and time averaged \%decrease of TRACP-5b (0.30). Parameters (correlation coefficient) which were correlated with \%increase of THBMD at 24 months were \%increase of LSBMD at 6 months (0.42), \%increase of THBMD at 6 months (0.69), baseline P1NP (0.36), time averaged \%decrease of P1NP (0.37), baseline TRACP-5b (0.29) and time averaged \%decrease of TRACP-5b (0.29). Although \%increase of BMD at 24 months was not correlated with disease activity of RA, taCRP was significantly correlated with taP1NP $(0.57)$ and taTRACP-5b $(0.45)$.

Conclusions: DMB was effective in RA-OP. Early response of BMD, baseline values of BTMs and response of BTMs were suggested to be the predictors of the efficacy of DMB in RA-OP. Inflamation of RA was correlated with not BMD but BTMs.

\section{References:}

[1] Hirano $Y$ et al. The predictors for 12 months efficacy of denosumab, an anti-RANKL antibody, on osteoporosis in patients with rheumatoid arthritis from multicenter study (TBCR-BONE). Ann Rheum Dis2016; 75(Suppl2): 94.

Disclosure of Interest: None declared

DOI: 10.1136/annrheumdis-2017-eular.3938

\section{Crystal diseases, metabolic bone diseases and bone diseases other than osteoporosis}

\section{AB0861 EXPRESSION CONTROL BY METHYLATION OF THE TLR1, TLR2, TLR4, IL1B, ALPK1 SLC2A9 AND SLC22A12 GENES IN MONOCYTES OF PATIENTS WITH GOUT}

N. Paniagua Díaz ${ }^{1}$, E.G. Tranquilino Batres ${ }^{1}$, A.P. López Flores ${ }^{2}$, A. Lozano Cardenas $^{2}$, E. Vallarino Reyes ${ }^{2}$, A.L. Alvarez Grijalva ${ }^{2}$, L. Sanchez Chapul ${ }^{1}$, C. Hernández Díaz ${ }^{3}$, L. Ventura Ríos ${ }^{3}$, A. Lopez Macay ${ }^{1}$. ${ }^{1}$ Enfermedades Neuromusculares, Instituto Nacional de Rehabilitacion; ${ }^{2}$ Ciencias de la vida, Instituto de Estudios Superiores Monterrey; ${ }^{3}$ LUMA, Instituto Nacional de Rehabilitacion, Mexico City, Mexico

Background: The gout is an inflammatory multifactorial disorder where the diet, age, sex, absorption regulation of uric acid in kidney and genetic, contribute to the onset of the disease. The balance of uric acid concentration not only depends on metabolism of purines but also on the clearance of uric acid, in which many proteins participate in the reabsorption and transport of urate. Is unknown if the peripheral blood leukocyte cells can change their expression and regulation mechanism of the urate transporters by the presence of uric acid in gout patients [1-4].

Objectives: Analyze changes in gene expression and the methylation pattern of the TLR2, TLR4, SLC2A9, SLC22A12, SLC22A3 and ABCG2 in neutrophils and peripheral blood monocytes from patients with gout and controls

Methods: The isolation of peripheral blood neutrophils and monocytes cells was performed by negative immunomagnetic selection (MACxpress kit, EUA). By flow citometry were analyzed the previously separate cell populations, mononuclear $(\mathrm{MN})$, polymorphonuclear (PMN) cells and neutrophils (N) (CD15, CD16, CD14). The DNA and RNA extraction was realized with a without columns kit and with Trizol technique. The gene expression analysis will be performed from total RNA by RT-PCR kit (Promega). Methylation analysis will be carried out the bisulfite conversion (ABCAM) from total DNA and HRM-PCR. For both studies, gene expression and methylation analysis are designed specific primers

Results: The biggest difference between asymptomatic gout patients $(n=12)$ and controls $(n=12)$, in the biochemical parameters (Table 1), is in the higher levels of uric acid and triglycerides that the patient presents. Actually, we've already evaluated the genetic expression of TLR1, TLR2, TLR4 and IL1b in mononuclear cells of 5 asymptomatic gout patients and 5 controls (Plot 1). Interestingly, IL1b is UP-regulated in sample group bye a mean factor of 16.350 and TLR2 is UP-regulated in sample group in comparison to control group by a mean factor of 3.686 .

Table 1. Characteristics of patients and controls

\begin{tabular}{lcc}
\hline & Patients & Controls \\
\hline Participants $(\mathrm{n})$ & 12 & 12 \\
Age $($ years) & 40.75 & 29.75 \\
BMl $\left(\mathrm{kg} / \mathrm{m}^{2}\right)$ & 29.27 & 24.05 \\
$\mathrm{SM} \mathrm{n}(\%)$ & 8.33 & 0 \\
Hypertension, $\mathrm{n}(\%)$ & 58.33 & 0 \\
Urate $(\mathrm{mg} / \mathrm{dL})$ & 8.35 & 4.87 \\
Glucose $(\mathrm{mg} / \mathrm{dL})$ & 84.83 & 81.33 \\
Cholesterol $(\mathrm{mg} / \mathrm{dL})$ & 196.33 & 175.25 \\
Tryglicerides $(\mathrm{mg} / \mathrm{dL})$ & 276.67 & 109.42 \\
Creatinine $(\mathrm{mg} / \mathrm{dL})$ & 1.02 & 0.79 \\
\hline
\end{tabular}

Conclusions: The asymptomatic patients with a higher mean of uric acid $(8 \mathrm{mg} / \mathrm{dL})$ and tryglicerides $(145.60 \mathrm{mg} / \mathrm{dL})$ had a higher expression of IL $1 \mathrm{~b}$ and TLR2 compared to controls. 